\title{
Biogas Situation and Development in Thai Swine Farm
}

\section{Wongkot Wongsapai ${ }^{1}$, Poon Thienburanathum ${ }^{2}$, Prasert Rerkkriengkrai ${ }^{3}$}

\author{
${ }^{1}$ Department of Mechanical Engineering, Faculty of Engineering, \\ Chiang Mai University, Chiang Mai, Thailand. \\ Phone: +66-81-681-2002 Fax: +66-53-892-375, e-mail: wongkot_w@yahoo.com
}

${ }^{2}$ Department of Civil Engineering, Faculty of Engineering, Chiang Mai University, Chiang Mai, Thailand.

\author{
Phone: +66-86-654-1202 Fax: +66-53-892-375, e-mail: orashun@gmail.com \\ ${ }^{2}$ Energy Research and Development Institute, Chiang Mai University, Chiang Mai, 50200 Thailand. \\ Phone: +66-53-942-007 Fax: +66-53-892-375, e-mail: prasert134@gmail.com
}

\begin{abstract}
The biogas technology in Thailand has been developed and adopted for many years, especially in the swine farm industry. The objectives of the biogas development are based on three main problems; i.e. (i) to reduce the appalling odor, (ii) to treat the wastewater, (iii) and to produce the biogas which is known as a renewable energy sources from the anaerobic digestion wastewater treatment processes. In this paper, the biogas situation including the technology development for swine farm in Thailand, which are mainly used the upflow anaerobic sludge blanket (UASB) bioreactor system, was discussed. From the results, we found that 11.6 million cubic meters of biogas per year would be produced under the government subsidization projects which gas then be used for various proposes; e.g. electricity generation, LPG or fuel oil substitution in boiler and heating system
\end{abstract}

Keywords: Biogas technology, Swine farm, Thailand

\section{Introduction}

Energy demand to meet the economic growth of Thailand has increased at a high rate for many years. Hence a need of a substantial knowledge, capacity building and amount of money to procure energy, both from domestic and foreign resources. Thailand adopted the Energy Conservation Promotion Act (ENCON Act), in the year 1992 which since then has been put into force to be the government instrument in determining regulatory measures, promoting efficient use of energy and renewable energy. Under the Act, the Energy Conservation Promotion Fund was established as a working capital to provide financial grants or support to energy conservation- and renewable energy-related activities. The renewable project, under ENCON Act promotion, mostly concerns utilization of renewable energy, which has less adverse impacts on the environment, and provides assistance to rural industry activities contributing to energy conservation, both in the agricultural sector and in the industrial sector [1]. Emphasis will be placed on providing suggestions, dissemination and transfer of renewable energy technologies, and on increasing energy efficiency by proven technologies, including projects on utilization of agricultural residues (e.g. bagasse and rice husks) or waste (e.g. manure from livestock) to produce energy. One of the most successful renewable energy development project in Thailand is the biogas for energy generation in swine farms project.

\section{Biogas Production}

Livestock raising has been rapidly expanding. Parallel with the growing number of livestock, increasing manure, residues and wastewater are improperly disposed and thus cause pollution. Traditional pig farms in Thailand normally manage their livestock wastes (e.g. manure and urine) by dumping them into a pond or series of pond [2]. However, without proper controlling the livestock wastes can be leaked or improperly discharged into natural stream or impoundment which can cause depleting the limited amount of oxygen in surface water and increasing amount of nitrogen, phosphorus, and chance of disease transmission $[3,4]$. These impacts can create significant damage to nearby body of water. Furthermore, with this traditional manure handling method, the farms can produce severe odor to plague their neighbors. The impact of odor normally creates social problem and reduces property value of neighborhood significantly [2].

As a strategic technology to release the above problems, biogas technology has been introduced into the swine industry for many years by supporting from the Germany's GTZ with, therefore, provides the following three advantages; i.e. (i) provide energy in the form of biogas, (ii) Alleviate wastewater treatment cost and reduce pollution caused by organic substances such as foul smell and flies, and (iii) produce by-product, the residues from the digestion process, which can be used as organic fertilizer to enrich the soil.

First demonstration of biogas system is established in 1992. Since 1995, Energy Policy and Planning Office (EPPO) of Thailand has been step up to promoting the implementation of biogas system in Thailand, so called the biogas for power generation 
promotion in livestock farms project phase I (19951998). Starting from the livestock farms, mainly on swine, by providing direct subsidy to farmers for the investment cost and all pre-investment cost. Phase II of the project were then operated from the year 1997 to 2003, followed by phase III from 2002 to 2009. Nowadays, since the energy price is increased, the benefits of energy from gas production can convince the farms easier to this investment, with approximately upto 33\% subsidization of the total investment cost to farm owners. Table 1 shows the summary of the biogas project, with all phases.

Table 1 Summary of Biogas promotion project in Thailand

\begin{tabular}{|c|c|c|c|c|}
\hline Item & Phase I & Phase II & Phase III & Total \\
\hline Period & $1995-1998$ & $1997-2003$ & $2002-2009$ & \\
\hline Subsidization budget (\$US) & 640,041 & $2,894,942$ & 24,373,708 & $27,908,692$ \\
\hline \multicolumn{5}{|l|}{ Technical data } \\
\hline Technology & UASB & UASB & UASB & \\
\hline Digestor Volume $\left(\mathrm{m}^{3}\right)$ & 10,000 & 46,000 & 280,000 & 336,000 \\
\hline Number of swine farm & 6 & 14 & $200 *$ & 20 \\
\hline \multicolumn{5}{|l|}{ Energy data } \\
\hline Biogas production (Million $\mathrm{m}^{3} / \mathrm{yr}$ ) & 1.6 & 10.0 & $76^{*}$ & 11.6 \\
\hline Electricity production (GWh/yr) & 1.63 & 12.50 & $88.92 *$ & 14.13 \\
\hline LPG (Million kg/yr) & 0.10 & 0.25 & $1.05^{*}$ & 0.35 \\
\hline Fuel oil (Million litres/yr) & - & 0.27 & $2.51 *$ & 0.27 \\
\hline
\end{tabular}

acetogenic, and methanogenic bacteria [6, 7]. These bacteria work as a team to produce approximately $60 \%-70 \%$ of Methane $\left(\mathrm{CH}_{4}\right), 38 \%-28 \%$ of Carbon dioxide $\left(\mathrm{CO}_{2}\right)$, and $2 \%$ of Hydrogen $\left(\mathrm{H}_{2}\right)$ and Hydrogen Sulfide $\left(\mathrm{H}_{2} \mathrm{~S}\right)$, all called biogas [6]. There are several factors affecting gas yield or bio-digestion rate, such as substrate temperature, available nutrients, volumetric load, flow-through time (retention time), $\mathrm{pH}$ level, nitrogen inhibition, agitation/mixing, and other inhibitory factors [6, 7]. A successful reactor is depended on the balance between and design and operation of the system to balance the nutrition and ambient for those kinds of bacteria,
Note: ${ }^{*}$ Forecast data; by the end of 2009

For project phase III, the ENCON fund has been implements by split the project into two major biogas sub-projects; the large and medium scale; i.e., between 60 to 600 and more than 600 livestock units (LU), respectively. By the end of 2009, these two subprojects is estimated for 2.2 millions of swine, which can reduce the impacts about 20 percent in overall swine in the country (there are around 10 millions of swine or 3,000 farm in 2006 [5]). However, these projects can create both direct and indirect benefits, such as energy saving and carbon credit claiming back to the country under clean development mechanism (CDM) which are now in progress.

\section{The System}

The biogas system basically consists of four main phases: pre-treatment, bioreactor, posttreatment, and energy utilization, as shown in Figure 1 [2, 6, 7]. Firstly, the pre-treatment module does preparing and adjusting the wastewater at a suitable condition. For the swine farms, it mainly traps the non-fermentation materials, such as sand and other large aggregates. Secondly, the bioreactor functions as a gas-generator. This bioreactor receives the wastewater from pre-treatment module as the input; then, produces biogas, solid wastes, and treated wastewater, the outputs. This process involves anaerobic fermentation activities, consists of three different bacterial communities: fermentative, which are the main workers of the system [7]. Furthermore, a good reactor can normally separate the reactor's outputs into three stages: solid waste (sludge), treated wastewater (effluence), and biogas effectively.

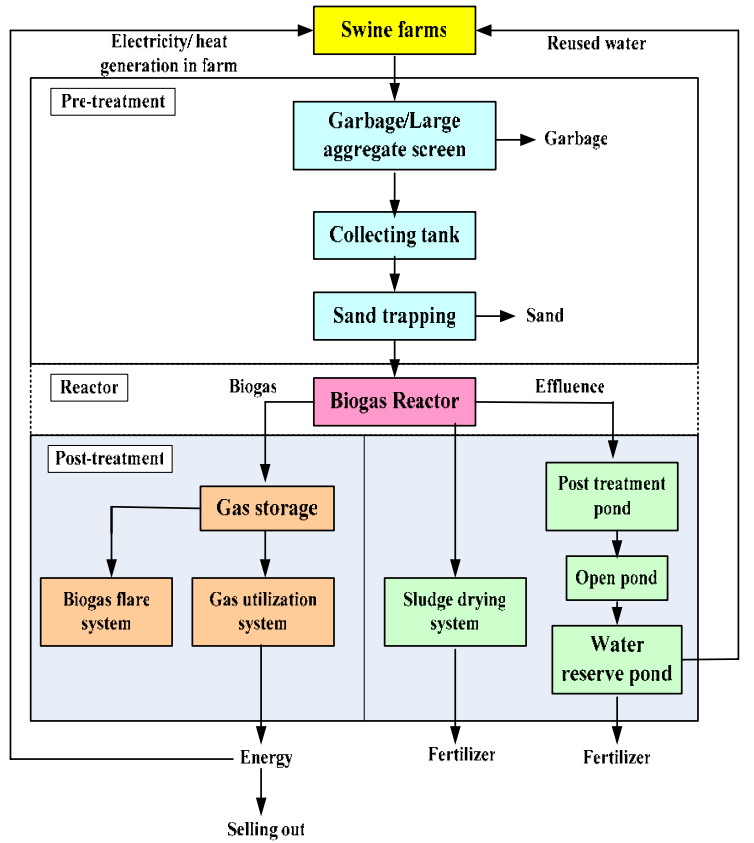

Figure 1 Typical biogas system for piggery farms. 
Thirdly, the post-treatment module includes two parts: post-water treatment and sludge drying system. The post-water treatment functions to maintain the effluence according to the environmental standards. Typically, the capacity of the posttreatment system is designed as about $10 \%-15 \%$ of total load. The treated wastewater can be reusable in farm's activities (e.g. washing). In some cases, directed effluence can be used as liquid fertilizer, particularly in nitrogen required plants. Another part of this module is sludge drying system. In any sunny zone, solar drying is the most effective method for harvesting the organic fertilizer. Fourthly, the energy utilization system is designed to transform the energy from the biogas to endusers effectively. One cubic meter of biogas $\left(60 \% \mathrm{CH}_{4}, 40 \% \mathrm{CO}_{2}\right)$ can give heating value as 20-25 MJ.

All details in perspective drawing of the 12,000 cubic meters Up-flow Anaerobic Sludge Blanket (UASB) biogas system, implemented in Thai swine farm, is illustrated in Figure 2 and examples of the biogas system shown in Figure 3 to 6.

The energy utilization system consists of three main parts: biogas storage (to buffer and equalize the fluctuation of biogas demand), flare (to release and burn the over production of biogas to the atmosphere), and biogas utilization/conversion. This system is generally implemented in two ways: utilizing the energy by directed heat and electricity. The directed heat is the most effective way of utilizing biogas. The examples of applications are radiant heater for rising piglet, warm-water-heated planar-type incubator, and gas boiler/burners system.
However, it has limitations in terms of applying practically. On the other hand, conversion of biogas to electricity, which is the most convenient way of energy utilization, is the most popular way of energy utilization although it has high energy loss (70\%-75\% at ambient condition). Approximately more than eighty percent of farms apply this method. The examples of the application are four-stroke diesel engines, converting diesel engines, modified gasoline engine, and stream engine (range from 1.1-1.7 $\mathrm{kWh} / \mathrm{m}_{3}$ ) [2].

It is hoped that the promotion of this project will create more confidence among farm owners in the system application to livestock raising and will attract those farm owners who have not yet established a biogas system to seriously think it over. This will also help create real market demand and hence system builders in the private sector will be keen in learning about the technology to help in their contracting for the job, which will further develop the market forces.

Under this project, a farm owner will have to invest in $67 \%$ of the construction and installation costs of the system. The ENCON Fund will provide a financial support covering $33 \%$ of the system cost to be spent for system designing advisory services and consultant services [1]. Such assistance will help increase the Financial Internal Rate of Return (FIRR) of the project. The farm owner will have to absorb the majority of the system building investment as well as all operational and maintenance costs.

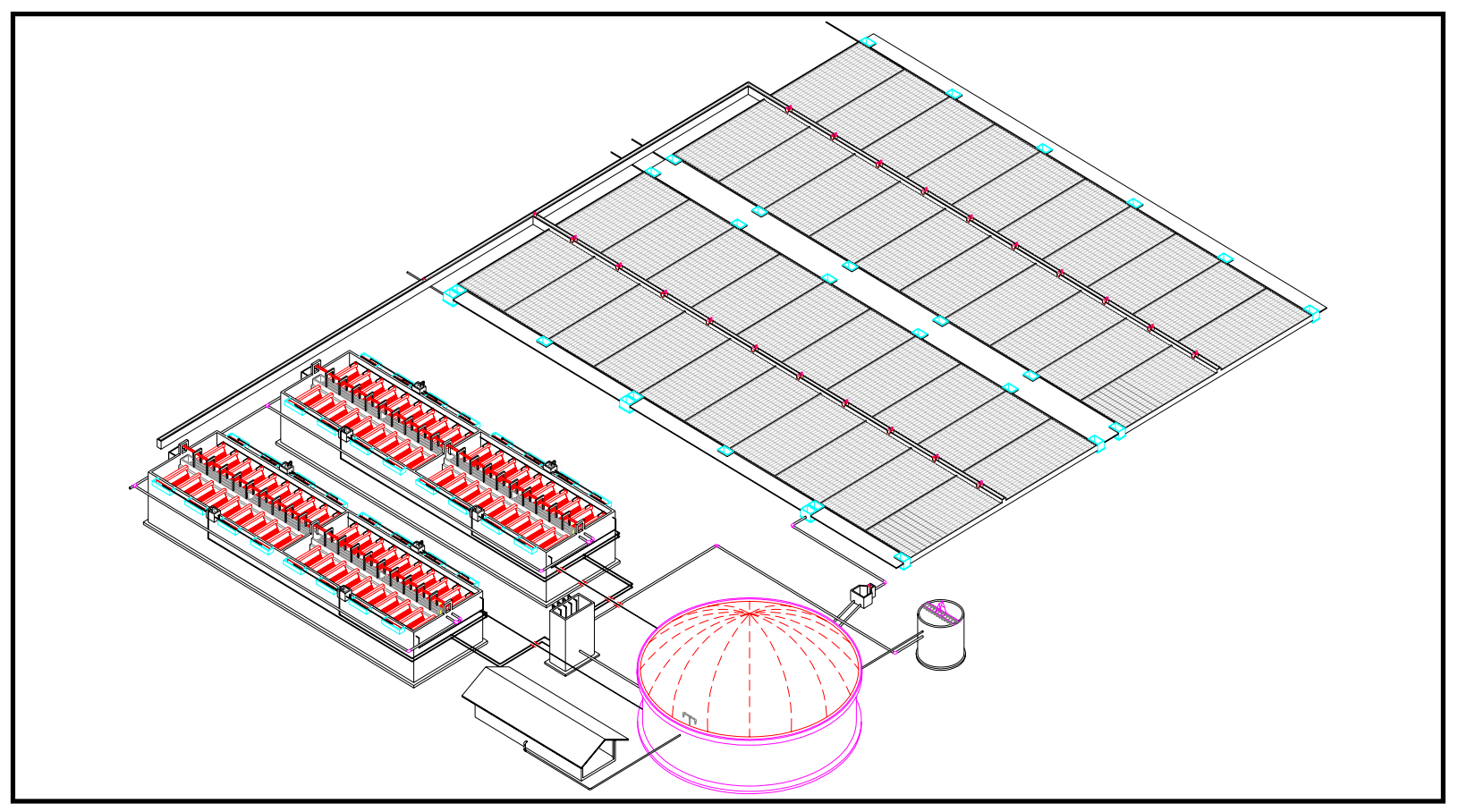

Figure 2 Up-flow Anaerobic Sludge Blanket (UASB) biogas system implemented in swine farm in Thailand. 


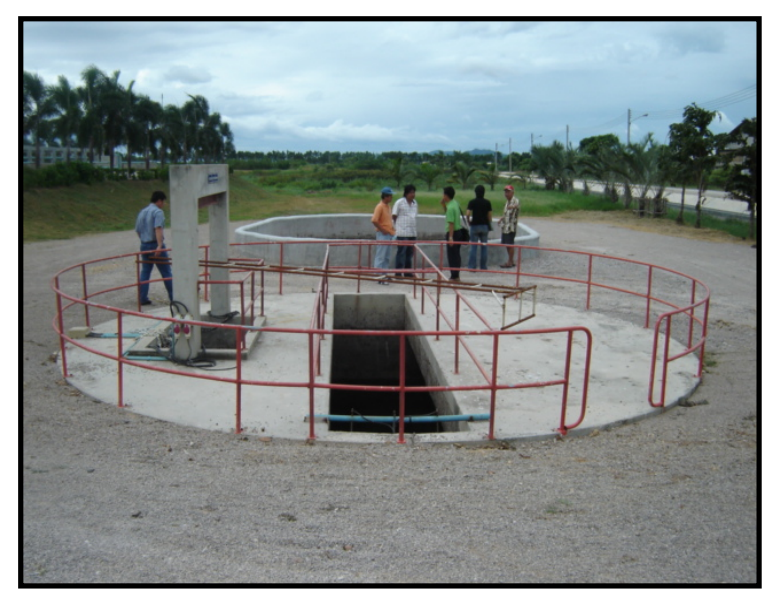

Figure 3 Wastewater collecting tank.

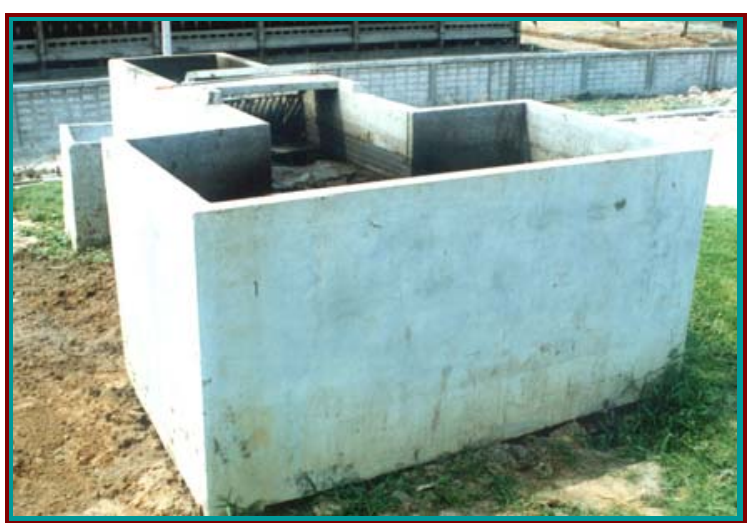

Figure 4 Sand trapping.

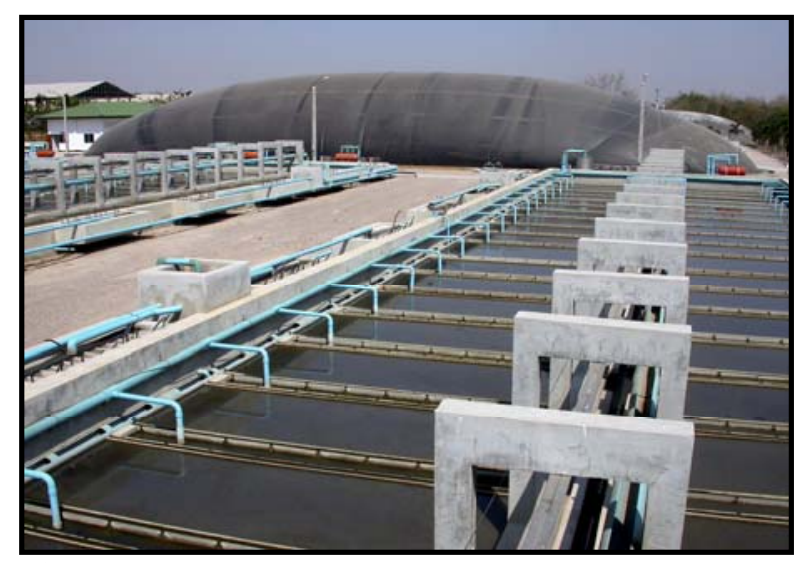

Figure 5 Buffer and gas storage tank (the upper capsule- shape) and H-UASB (below).

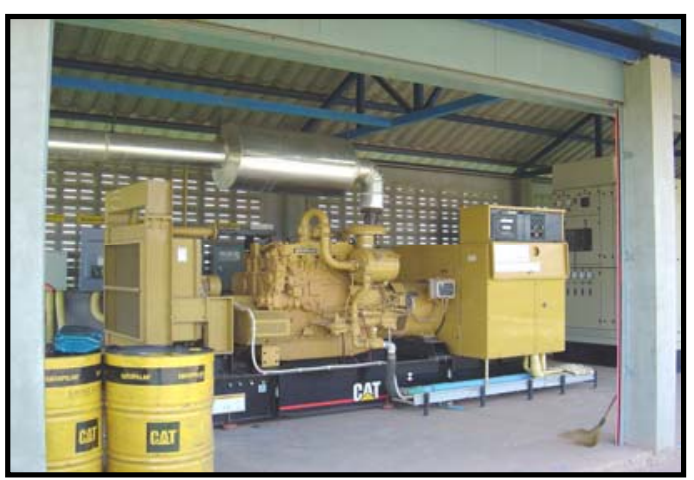

Figure 6 Gas-to-electricity generator.

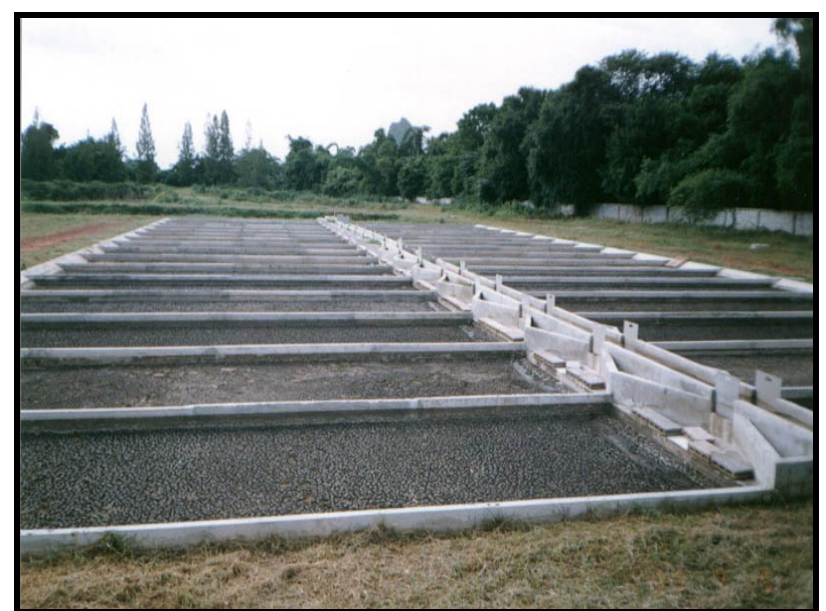

Figure 7 Sludge drying.

\section{Conclusions}

Under subsidization from the government, biogas technology from wastewater treatment has been adopted in Thailand for more than 20 years, particularly in swine farms. The benefits to the farmers consist of the reduction of environmental impacts, less odor reduction, less land-use for wastewater treatment system, and renewable energy from biogas generation. The biogas then be converted to electricity generation in the farm and/or used as direct heat for LPG substitution in household sector. Organic fertilizer is another by-product from such a system. We can conclude that the Promotion Program for Biogas Production in Small and Medium-sized Livestock Farms project bring the direct and indirect benefits to the society much more than the typical anticipation.

\section{Acknowledgments}

The authors would like to thank the Energy Conservation Promotion Fund (ENCON Fund) for financial support of the biogas for swine farms project and the Energy Policy and Planning Office (EPPO), Ministry of Energy for supporting throughout our works with valuable comments. All participated farms for research and all supports. We remain culpable for any remaining errors.

\section{References}

[1] Energy Policy and Planning Office (EPPO), Implementation Achievement of the Voluntary Program During the period 19965-1999 Under the Energy Conservation Program, Energy Conservation Promotion Fund, Thailand, 2001.

[2] Thiengburanathum, Poon , The impacts of biogas system implementation to piggery farm industry in Thailand, International Conference on Green and Sustainable Innovation, Novermber $29^{\text {th }}$-December $1^{\text {st }}, 2006$, Thailand. 
[3] Miner, R.J., Managing Livestock Wastes to Preserve Environmental Quality, Iowa State University Press, Ames, 2000

[4] Hohlfeld, J., Production and Utilization of Biogas in Rural Areas of Industrialized and Developing Countries, GTZ , Germany, 1986

[5] Department of Livestock Development, Statistics of livestock in Thailand, DOLD, Ministry of Agriculture, Thailand, 2007. The data can be downloaded from www.dold.go.th/statistics

[6] Hohlfeld, J., Production and Utilization of Biogas in Rural Areas of Industrialized and Developing

Countries, GTZ , Germany, 1986

[7] Speece, R.E., Anaerobic Biotechnology for Industrial Wastewaters, Archae Press, Nashville, Tenn.,1996. 